IZA DP No. 9076

Offline Effects of Online Connecting: The Impact of Broadband Diffusion on Teen Fertility Decisions

Melanie Guldi

Chris M. Herbst

May 2015 


\title{
Offline Effects of Online Connecting: The Impact of Broadband Diffusion on Teen Fertility Decisions
}

\author{
Melanie Guldi \\ University of Central Florida
}

\author{
Chris M. Herbst \\ Arizona State University \\ and IZA
}

\author{
Discussion Paper No. 9076 \\ May 2015
}

IZA

P.O. Box 7240

53072 Bonn

Germany

\author{
Phone: +49-228-3894-0 \\ Fax: +49-228-3894-180 \\ E-mail: iza@iza.org
}

\begin{abstract}
Any opinions expressed here are those of the author(s) and not those of IZA. Research published in this series may include views on policy, but the institute itself takes no institutional policy positions. The IZA research network is committed to the IZA Guiding Principles of Research Integrity.

The Institute for the Study of Labor (IZA) in Bonn is a local and virtual international research center and a place of communication between science, politics and business. IZA is an independent nonprofit organization supported by Deutsche Post Foundation. The center is associated with the University of Bonn and offers a stimulating research environment through its international network, workshops and conferences, data service, project support, research visits and doctoral program. IZA engages in (i) original and internationally competitive research in all fields of labor economics, (ii) development of policy concepts, and (iii) dissemination of research results and concepts to the interested public.
\end{abstract}

IZA Discussion Papers often represent preliminary work and are circulated to encourage discussion. Citation of such a paper should account for its provisional character. A revised version may be available directly from the author. 


\section{ABSTRACT \\ Offline Effects of Online Connecting: The Impact of Broadband Diffusion on Teen Fertility Decisions}

Broadband (high-speed) internet access expanded rapidly from 1999 to 2007. This expansion is associated with higher economic growth and labor market activity. In this paper, we examine whether the rollout also affected the social connections teens make. Specifically, we look at the relationship between increased broadband access and teen fertility. We hypothesize that increasing access to high-speed internet can influence fertility decisions by changing the size of the market as well as increasing the information available to participants in the market. We seek to understand both the overall effect of broadband internet on teen fertility as well as the mechanisms underlying this effect. Our results suggest that increased broadband access explains at least thirteen percent of the decline in the teen birth rate between 1999 and 2007. Although we focus on social markets, this work contributes more broadly to an understanding of how new technology interacts with existing markets.

JEL Classification: J13, J18

Keywords: $\quad$ fertility, birth rates, broadband, new media

Corresponding author:

Chris M. Herbst

School of Public Affairs

Arizona State University

411 N. Central Ave., Suite 420

Phoenix, AZ 85004-0687

USA

E-mail: chris.herbst@asu.edu 


\section{Introduction}

In 2010 , the U.S. teen birth rate was 34.3 births per 1,000 women ages 15 to 19,44 percent lower than its recent peak in 1991 and 64 percent lower than the historic high recorded in 1957. This reduction is showing no signs of slowing down: since 2007, the teen birth rate has fallen by nearly one-fifth. In response, policymakers and scholars are now devoting significant attention to understand why these dramatic changes have occurred. Researchers have explored the role of technology (contraception), legal access (laws regulating minor access to abortion or contraception), and the tax and transfer system (cash assistance and Medicaid) as possible explanations for the observed decline in teen fertility. A recent paper by Kearney and Levine (2012) tests a number of these factors and finds that, taken together, they account for only a small fraction of the reduction in teen birth rates between 1991 and 2008. Indeed, the authors conclude that "no policy or other environmental factor can be pinpointed as contributing substantially to the decline" (p. 28).This suggests that the principal cause (or causes) of the recent decline have not been identified by these first-order economic and policy explanations.

As a result, scholars have started pursuing alternative explanations. For example, two recent working papers examine the role of media exposure via-a-vis MTV's popular show 16 and Pregnant in accounting for the decline in teen fertility (Kearney \& Levine, 2014; Tredeaux, 2014). Although these papers utilize somewhat different research designs, both conclude that the program, which first aired in June 2009, produced sizable declines in teen ferility. For example, estimates from Kearney and Levine (2014) imply that the introduction of 16 and Pregnant along with its companion programs (Teen Mom and Teen Mom 2) explain approximately one-third of the decline in teen births by the end of 2010 . 
In this paper, we examine a related though distinct explanation for the drop in teen births: the rapid diffusion of broadband internet providers. Currently, 98 percent of U.S. households reside in areas with broadband internet access, and 70 percent of households have such a high-speed connection in the home, an increase from three percent in 2000 (National Telecommunications \& Information Administration, 2013; Zichuhr \& Smith, 2013). Conversely, the proportion of households using dial-up connections plummeted from 34 percent in 2000 to three percent today. Moreover, the rise in home broadband utilization has been ubiquitious, increasing even in rural areas, where access and adoption was initially slow. Over the last decade, there has been a 3.5fold increase in the fraction of rural households with a high-speed internet connection (Horrigan, 2007; Zichuhr \& Smith, 2013).

Teenagers have taken significant advantage of this reshaped internet landscape, becoming key consumers of "new media" (i.e., digital) content and using social media to create and expand friendship networks. Fully 95 percent of teens regularly use the internet, a percentage that has remained virtually unchanged over the past decade and which exceeds internet use rates by all other age groups (Madden et al., 2013). In addition, 93 percent of teens own or share a laptop or desktop computer at home, and nearly one-quarer own a tablet computer. ${ }^{1}$ Such widespread access to broadband internet has dramatically altered the intensity and manner in which teens interact, socialize, and exchange information. Teen computer users spend over two hours per day on recreational (in-home) computer use, with visits to social media sites (e.g., MySpace and Facebook) and YouTube accounting for most of that time (Rideout et al., 2010). Indeed, at least three-quarters of teens have an active MySpace or Facebook profile, and one-quarter regularly use Twitter (Madden et al, 2013; Lenhart, 2012a; Rideout et al., 2010). The typical teen Facebook user

\footnotetext{
${ }^{1}$ Rates of teen internet use exceed 90 percent for nearly every demogrpahic group-including non-whites, those in rural areas, and those with low-education parents-while rates computer ownership are consistently well above 60 percent (Madden et al., 2013).
} 
has 300 friends, and one-third are friends with individuals they have not met in person (Madden et al., 2013). Finally, 37 percent of teens regularly participate in video chats using Skype, Googletalk, or iChat, and many create their own video content for others to consume (Lenhart, 2012b).

Our simple conceptual framework posits that the diffussion of broadband internet may influence teenage fertility through several channels. The first mechanism operates through the information and social networking effects of broadband diffusion. Specifically, broadband access is an efficient means of reducing search frictions primarily by lowering the cost of seeking and sharing information. This may have implications for the regularity and nature of the interactions with potential intimate partners, the quantity and quality of information obtained on sexual practices and health, and an understanding of the costs and benefits of raising a child. Given the large amount of time that teens spend on internet-related activities, a second mechanism is through the displacement of other forms social interaction. In others words, the time spent communicating with others via social media could supplant face-to-face interaction, thereby reducing the frequency of sex and, in turn, the birth rate. A final mechanism operates via changes in current or perceived future employment opportunities. Insofar as broadband diffusion increases local economic activity, the rise in income could have positive or negative effects on the teen birth rate that depend on whether the income or substitution effect dominates the childbearing decision. Overall, the relationship between broadband diffusion and teen fertility is theoretically ambiguous, and thus warrants empirical analysis.

To examine the impact of broadband diffusion on teen fertility, we draw on zip code level data on broadband internet deployment from the Federal Communications Commission (FCC) Form 477. The FCC requires broadband providers to report whether there is at least one household 
or business subscriber (at least 200 kilobits per second) in a given zip code. We use these data to construct a measure of the degree to which a given county has access to broadband internet providers. This information is then merged to county level natality data from the National Center for Health Statistics (NCHS), resulting in a panel of counties over the period 1999 to 2007. This period is chosen because, as will be shown, it represents the years during which broadband was aggressively rolled out across the U.S. Thus, our identification strategy relies on the differential access to broadband internet across space (i.e., counties) and time (i.e., years). Although our primary outcome is the teen birth rate, we conduct a number of auxiliary analyses to explore the abortion rate, intensity of sexual activity, contraceptive behavior, and rates of sexually transmitted diseases. Therefore, a key goal of the paper is to understand not only the overall effect of broadband internet on teen birth rates, but also the mechanisms by which it primarily affects birth rates.

Our results suggest that increased broadband access is associated with a reduction in the teen birth rate. Specifically, our best estimate implies that the national broadband rollout between 1999 and 2007 can explain at least 13 percent of the decline in teen births during this period. Our evidence suggests that these drops are driven by changes in metropolitian areas. We then explore the relationship between increased broadband access and teen risky behaviors. The signs of our estimates are consistent (though statstically insignificant) with the growing use of contraception, a decrease in sexual activity, and a decrease in the gonorrhea rate, all of which would act to decrease the birth rate. However, we do not find any evidence that broadband access influenced the abortion rate. Although we focus on social markets, this work also contributes more broadly to our understanding of how new technology interacts with existing markets. 
The remainder of the paper proceeds as follows. Section II describes the conceptual framework for understanding the mechanisms through which broadband internet may influence teen fertility outcomes. Section III reviews the relevant literature on the economic and social impacts of broadband diffusion. Section IV introduces the data, while Section V discusses the empirical model. We present the estimation results in Section VI, and provide concluding comments in Section VII.

\section{Conceptual Framework}

Standard economic models begin with the assumption that fertility decisions are made in a series of steps, beginning with the decision about whether to have sex (Levine, 2004). Decisions are then made regarding the level of contraceptive intensity. If a pregnancy occurs, women must decide between aborting the pregnancy and giving birth. Two assumptions underlie the standard model. Women are assumed to act with perfect information and without search costs throughout this decision-making process, and they maintain perfect control over fertility outcomes. Based on these considerations, the model predicts that decreasing the costs associated with bearing and raising children increases the likelihood that a pregnancy will occur and increases the likelihood that a pregnancy will end with a birth (while reducing the probability of having an abortion). In the present paper, we assume that teens do not have perfect information and that search costs may exist. Relaxing these assumptions suggests that there are several mechanisms through which broadband diffusion might influence the birth rate. We consider each mechanism in turn.

The first mechanism operates through broadband's effect on information and media consumption. Broadband provides an efficient means of reducing search frictions primarily by reducing the cost of seeking information (e.g., on potential partners, affordable and effective contraception technologies, anecdotal evidence on parenting, and the costs and benefits of raising 
a child). Offline information markets tend to be highly decentralized, thereby increasing the time and psychic costs of finding reliable information on contraception and parenting. Online markets, on the other hand, are better organized and thus have the potential to mitigate these search frictions. Indeed, survey evidence suggests that teens are making increased use of on-line information. From 2004 to 2009, teen consumption of print media declined 37 percent. In its place, one-half of teens report ever having read a blog, and 55 percent report ever having investigated health information on-line (Rideout et al., 2010). ${ }^{2}$ In addition, the internet is now a key mode through which individuals consume media, and broadband diffusion has hastened this development. Indeed, activities related to media consumption-for example, watching YouTube videos, playing video games, or visiting web sites - account for nearly half the time teens spend on the home computer (Rideout et al., 2010). To the extent that media consumption has an effect on individual behavior, broadband access could have a large influence on the birth rate.

Another mechanism focuses on the powerful role played by participation in social networking environments, including MySpace, Facebook, Twitter, and Snapchat. ${ }^{3}$ Such services stimulate and centralize social interactions as well as serve as information-sharing venues in a variety of ways that may influence the teen birth rate. An obvious effect of social media is to lower search frictions for potential partners by reducing the pecuniary and psychic costs relative to searches in traditional environments. In fact, websites such as FunDateCity and MyLOL (which boasts a membership of over 300,000 worldwide) are designed specifically to promote teen dating. Moreover, anecdotal evidence suggests that teens increasingly use a variety of non-dating websites and services such as Instagram, Tumblr, and Xbox LIVE to seek out romantic relationships. ${ }^{4}$

\footnotetext{
${ }^{2}$ Fully 66 percent of females ages 15 to 18 have ever searched for health information on-line (Rideout et al., 2010).

${ }^{3}$ The services of MySpace (2003), Facebook (2004; 2006 for teens), Twitter (2006), and Snapchat (2011), and others we mention were not all available during our period of study; we include these as examples of "social media".

${ }^{4}$ For example, see: http://www.huffingtonpost.com/2013/03/02/teens-discuss-online-relationships-and_n_2792601.html and http://dating.lovetoknow.com/Teen_Online_Dating.
} 
Another avenue for a social media effect is through a peer effect in which social norms, behaviors, and information are transmitted throughout one's network and are in turn adopted by others in that network. Still another avenue is through the displacement of other forms social interaction. In others words, the time spent engaging with others via social media could supplant - through a form of "incarceration"-face-to-face interaction, thereby reducing the frequency of sex and in turn the birth rate. ${ }^{5}$ Such a possibility finds strong support in recent surveys of teens. Relative to a few years ago, teens are substantially less likely to socialize in person or over the phone (using a landline or cell), and are more likely to communicate via text messages (Lenhart, 2012a). Furthermore, a non-trivial fraction of teens - as high as 28 percent in one study-engage in "sexting," defined as the electronic transmission of sexually explicit images or messages (The National Campaign, 2008; Temple et al., 2012).

A third mechanism may operate through changes in current or perceived future employment opportunities. Previous research finds that local broadband diffusion is associated with increased employment growth (Atasoy, 2013; Kolko, 2012). To the extent that broadband access increases local economic activity and living standards-primarily by way of increased earnings - a baseline prediction suggests that broadband may lead to an increase in the birth rate, assuming children are normal goods. However, additional income from local broadband growth may reduce the birth rate (especially the teen birth rate) because of the increased opportunity costs associated with bearing and raising children. Income-driven reductions in the birth rate may also occur because individuals previously not using contraception may now be able to afford a basic level of protection, while those already using contraception may purchase a higher-quality (and

\footnotetext{
${ }^{5}$ Incarceration effects are found to exist through the consumption of other forms of media. For example, Dahl and DellaVigna (2009) find that rates of violent crime are lower on the same day that popular violent movies are released in a given local area, which they attribute to an incarceration effect.
} 
presumably more effective) level of protection. Aside from these income-driven changes in fertility, it is plausible that the types of jobs created by broadband diffusion have implications for fertility decisions. For example, if broadband is associated with increased telecommuting or flextime work, such arrangements might lead to increased birth rates among working-age women, as the cost of bearing and raising children would likely decline. More importantly, new work arrangements might lead to lower teen birth rates if adults are more likely to supervise their teenage sons and daughters. ${ }^{6}$

Implicit in the preceding discussion is the notion that broadband diffusion can influence birth rates at two key points in the fertility decision-making process (Kane \& Staiger, 1996; Levine, 2004). Specifically, we relax the perfect information assumption of the standard fertility model. With broadband diffusion, teens gain additional information prior to pregnancy and between pregnancy and birth. The first point occurs when decisions are made about the level of sexual activity and contraceptive intensity. Teens might increase the level of contraceptive intensity or decrease the level of sexual activity in response to the increased opportunity cost of having a child. Additionally, increased information on contraception and where to obtain it may increase teens' use of various forms of birth control. The increased number of potential partners (via meeting others online and widening the size of the dating market) may increase the probability of sexual activity, while meeting virtually instead of face-to-face may decrease the probability of sexual activity. Predictions regarding sexual activity and use of contraception conditional on sexual activity are therefore ambiguous. The second point happens through changes in women's decisionmaking after a pregnancy occurs. Since broadband diffusion increases economic activity, additional income (assuming children are normal goods) could increase the number of pregnancies

\footnotetext{
${ }^{6}$ Dettling (2014) provides evidence that increased at-home broadband access leads to higher rates of married female labor force participation, suggesting that the ability to work from home is a key factor for this demographic.
} 
ending in birth. At the same time, the opportunity cost of giving birth rises (due to forgone wages), suggesting that economic activity could reduce the number of pregnancies ending in a birth.

\section{Relevant Literature}

There is a small but growing body of work exploring the economic and social implications of broadband diffusion. Perhaps the most widely studied outcomes are those dealing with labor market behavior and local economic development. For example, using a panel of U.S. counties between 1999 and 2007, Atasoy (2011) finds that the introduction of broadband into a county increases the employment rate by 1.8 percentage points. Comparable results (qualitatively) are produced by Kolko (2012), who relies on zip code level panel data over a similar time period, and who uses a different identification strategy as well as more detailed local controls. Interestingly, both studies find that broadband diffusion is particularly important to economic growth in areas with lower population densities.

Recent work also examines skill complementarities with respect to broadband diffusion. Akerman, Gaarder, and Mogstad (2013) combine broadband diffusion data with firm level information in Norway, and find that broadband adoption increases the productivity of skilled labor, while lowering the productivity of unskilled labor. Consistent with this, the authors find that broadband diffusion increases the wages of the former group and lowers the wages of the latter group. Taken together, the findings of these studies suggest that broadband access increases the opportunity cost of having a child among high-skilled individuals. Dettling (2014), however, shows that increasing broadband connectivity at home leads to greater labor force participation rates among married women with children, suggesting that greater connectivity improves labor market outcomes for this demographic. 
A small number of studies have begun exploring an array of social outcomes. Bellou (2013) examines the impact of U.S. broadband diffusion (measured at the state-level) on marriage decisions for non-Hispanic whites ages 21 to 30. The author finds that broadband availability is associated with large, positive increases in the marriage rate, equivalent to a 13 to 30 percent increase from the counterfactual marriage rate. In addition, Bhuller, Havnes, Leuven, and Mogstad (2013) examines whether broadband diffusion has implications for sex crimes. Using Norwegian internet and sex crime data, the authors find internet use substantially increases reports of but also charges and convictions for rape and other sex crimes.

This is the first paper we are aware of that examines the fertility effects of broadband diffusion. It contributes to an established literature studying the implications of media access for a variety of social and familial outcomes. ${ }^{7}$ For example, Olken (2009) finds that the introduction and proliferation of radio and television signals in Indonesian villages decreased social capital. La Ferrara et al. (2012) study the implications of soap operas in Brazil, and find that the spread of these television shows reduced fertility rates. A related paper by Jensen and Oster (2009) shows that the diffusion of cable television in India reduced fertility rates and reshaped women's attitudes toward son preferences and female autonomy. In addition, this paper is tangentially related to a small set of studies exploring the health consequences of technology and mobile devices. A recent paper by Palsson (2014), for example, finds that the rapid adoption of smart phones (with 3G access) produced higher rates of child injuries as well as increases in risky parental behaviors. Similarly, a large number of studies investigate the impact of cell phone use on car accidents, with many finding a positive effect (e.g., Redelmeier \& Tibshirani, 1997; Bhargava \& Pathania, 2013).

${ }^{7}$ Dahl and Price (2012) provide a comprehensive review of the literature. 


\section{Data Sources}

\section{Broadband Data}

We rely on the FCC's Form 477 to construct the measure of broadband availability. ${ }^{8}$

These data, which have been used elsewhere to study the effect of broadband deployment (e.g., Atasoy, 2011; Kolko, 2012), report the number of broadband providers that serve at least one customer in a given zip code. Broadband providers are defined as those offering services at 200 kilobits per second or faster; these typically include telephone-based DSL lines, cable modems, and satellite services. Between 1999 and 2007, these data were recorded by the FCC biannually (in June and December) at the zip code level. However, the agency in 2008 began reporting these data at the county level, hampering our ability to construct a comparable measure of broadband access in the pre- and post-2008 period. ${ }^{9}$ We do not view this as problematic since, as shown in Figure 1, nearly all counties had at least one broadband provider by 2007. Therefore, we limit our analysis to the years 1999 to 2007 . We utilize the December reports to construct the measure of broadband access.

These data are not without their limitations. First, the definition of high-speed broadband internet used in the original Form 477 is now outdated. The American Recovery and Reinvestment Act of 2009 stipulated that providers must sell products at speeds of at least 768 kilobits per second to be deemed "high-speed." A second limitation is that the Form 477 data measure the availability of broadband rather than adoption or utilization. However, given the time series evidence on household use of broadband reported in Zickuhr and Smith (2013), it is apparent that access and

\footnotetext{
${ }^{8}$ Data were obtained from http://transition.fcc.gov/wcb/iatd/comp.html on 6/20/2012. As described within the documentation, these data are "lists of geographical zip codes where service providers have reported providing high-speed service to at least one customer as of December 31, [of the relevant year]. No service provider has reported providing high-speed service in those zip codes not included in this list. An asterisk $(*)$ indicates that there are one to three holding companies reporting service to at least one customer in the zip code. Otherwise, the list contains the number of holding companies reporting high-speed service. The information is from data reported to the FCC in Form 477."

${ }^{9}$ Through correspondence with the FCC, we were informed that county level counts are not available in the 1999 to 2007 period.
} 
adoption closely track one another. Third, the data do not allow researchers to distinguish between consumer versus business use, advertised versus actual speeds, and whether the provider serves entities throughout the entire zip code as opposed to a portion of it. Despite these limitations, the FCC data represent the only publicly available archive documenting the U.S. broadband rollout over a meaningful period of time. Furthermore, Kolko (2012) argues that the number of providers in a local area is a relevant proxy for internet access because the goal of broadband policy is to increase - through a variety of mechansims - the supply of services in that area.

Our main analysis is performed at the county level. Armed with FCC data on the number of providers by zip code, our measure of broadband diffusion is defined as the population-weighted percentage of zip codes in a given county with at least one provider. To create the measure, we utilized SAS geographic information, Census ZCTAs, zipcode-to-county crosswalks (available on the Missouri Census Data Center website), and a list of county FIPS codes available from the National Bureau of Economic Research (NBER) to create a county-by-year list of zip codes over the period 1999 to $2007 .{ }^{10}$ We then merged the FCC data onto this master list, and assumed that zip codes without matches did not have at least one broadband provider in December of that year. ${ }^{11}$ Next, we weighted the broadband measure by the population in a zip code in 2000 to create county or state level measures of the population-weighted percentage of the relevant area with at least one provider. Finally, we merged this with our county or state level outcomes and covariates, which

\footnotetext{
${ }^{10}$ We utilize information on the Missouri Census Data Center page to map postal zip codes into county geographic units: http://mcdc.missouri.edu/websas/geocorr12.html, and information on county FIPS codes available on the National Bureau of Economic Research data page: http://www.nber.org/data/ssa-fips-state-county-crosswalk.html.

${ }^{11}$ Our measure of broadband diffusion is similar to, though distinct from, the measure used in previous studies. For example, our measure is most similar to Atasoy (2011) who creates a population-weighted binary indicator for the presence of any broadband provider in a given zip code (i.e., ZCTA). Kolko (2012) creates a linear measure of access, assigning a value of zero to zip codes with zero providers, a value of two to zip codes with one to three providers, and the actual number of providers to zip codes with more than three providers.
} 
are described below. The analysis sample is limited to 48 states and the District of Columbia. ${ }^{12}$ Our main analysis dataset includes 22,824 county-year combinations.

Figure 1 shows the evolution of U.S. broadband diffusion over the period 1999 to 2007. We display the population-weighted and -unweighted versions of the broadband measure. Consistent with previous work, we find a dramatic rise in broadband coverage. In 1999, 75 percent of the county (access weighted by zip code population) had at least one broadband provider serving at least one customer. By 2007, this proportion rose to nearly 99 percent. The unweighted measure of broadband provider presence follows a similar trend. It is also apparent from Figure 1 that virtually all of the increase occurred between 1999 and 2003; for most counties, rates of broadband diffusion changed very little after 2003. It is useful to compare these rates of broadband diffusion to individual-level data on take-up of home broadband internet. Each year since 2000, Pew Research Center's Internet and American Life Project has asked a nationally representative sample of U.S. adults whether they have a high-speed broadband internet connection. In 2000, three percent had a home broadband connection, increasing to 47 percent by 2007 (Zickuhr \& Smith, 2013)..$^{13}$

\section{Natality, Gonorrhea, and Abortion Data}

We examine a number of outcomes in this study, all drawn from different sources. First, we utilize the National Center for Health Statistics restricted-use geo-coded natality data to construct county-by-year counts of the number of births to individuals ages 15 to 19 as well as data from the Surveillance, Epidemiology, and End Result (SEER) Program to construct county-

\footnotetext{
${ }^{12}$ We exclude Hawaii and Louisiana. We omit Louisiana counties due to changes in the infrastructure, including broadband, as a result of hurricane Katrina. Hawaii is omitted due to missing population information.

13 The trend depicted by Pew Research Cener's analyses accords with data collected by other entities. For example, the U.S. Department of Commerce (2010) estimates that broadband internet use rose sevenfold, from nine percent to 64 percent between 2001 and 2009. Simultaneously, households with internet use at home (regardless of connection speed) rose from 18 percent in 1997 to 62 percent in 2007 (Current Population Survey, 1984-2009). Source: U.S. Census Bureau http://www.census.gov/hhes/computer/files/Appendix-TableA.xls.
} 
by-year counts of the population of women ages 15 to $19 .{ }^{14} \mathrm{We}$ calculate the county-by-year teen birth rate, the primary outcome in this study, over the period 1999 to 2007. Second, county level gonorreha rates (number of cases for any age or gender divided by county population per 100,000) are available for the period 1999 to 2007 for a subset of 30 states. The authors obtained data for periods earlier than 2003 directly from the Centers for Disease Control (CDC). Third, abortion data were obtained from a third party website containing information for 33 states over the study period. ${ }^{15}$ The abortion rate is calculated as the total number of abortions in a county (regardless of age) divided by county population per 1,000. We linked information on the teen birth rate, county gonorrhea rate, and county abortion rate to our county-level broadband data over the period 1999 to 2007 .

\section{County Level Covariates}

Our regression models control for a variety of observable county characteristics. One set of controls, which includes population density, the unemployment rate, per capita personal income, the fraction white, the fraction Hispanic, and the share of the population with a bachelor's degree, is drawn from the Census Bureau and the Bureau of Labor Statistics. In addition, we draw on the Bureau of Economic Analysis' Regional Information System (REIS) to generate county-by-year expenditure data on such government programs as Medicaid, Supplemental Security Income (SSI), Temporary Assistance to Needy Families (TANF), and the Supplemental Nutritional Assistance Program (SNAP). ${ }^{16}$

We also utilize state level data in the analysis. Additional measures of teen risky behaviors are obtained from the Youth Risk Behavior Surveillance System (YRBS) including whether the

\footnotetext{
${ }^{14}$ SEER population data can be retrieved from the National Cancer Institute at http://seer.cancer.gov/popdata/.

${ }^{15}$ Abortion data source: http://www.johnstonsarchive.net/policy/abortion/\#UC accessed 4/15/14 to 4/22/14.

${ }^{16}$ REIS data can be accessed via http://www.bea.gov/regional/.
} 
teen is currently sexually active; if so, whether the teen used a method to prevent pregnancy at last intercourse; and finally, whether the teen has ever had sexual intercourse. For these data only nine states report information on the variables of interest throughout our study period. ${ }^{17}$ We also obtain state level teen gonorrhea rates from the CDC's ATLAS tool for the period 2000 to2007. ${ }^{18}$

Table 1 provides summary statistics for the broadband and outcome variables examined in the analysis. Over the period 1999 to 2007, approximately 93 percent of counties contained at least one broadband internet provider serving at least one customer. The average county level teen birth rate over this period is 47 births per 1,000 women ages 15 to 19. However, as shown in Figure 1, this masks substantial heterogeneity throughout the study period: the teen birth rate declined from approximately 52 births in 1999 to 45 births in 2004 before rising slightly to 47 births 2007 . Additionally, over the study period, teen birth rates in metro counties are lower than those in nonmetro counties, suggesting that we should test for the possibility that broadband diffusion had different effects on teen fertility decisions in metro versus non-metro areas.

\section{Empirical Model}

To study the impact of broadband internet diffusion on teen birth rates, we estimate regressions of the following form:

$$
Y_{c t+1}=\beta_{0}+\beta_{1} B B p c t_{c t}+\beta_{2} B B p c t_{c t} * \text { Metro }_{c}+\beta_{2} X_{c t}+\gamma_{c}+\tau_{t}+\delta_{c t}+\varepsilon_{c t}
$$

where $Y_{c t+1}$ is the teen birth rate in county $c$ in year $t+1$ and is calculated as the number of children born to women ages 15 to 19 divided by the number of women ages 15 to 19 in each county-year cell. In some regressions, we interact $B B p c t_{c t}$ with $M_{e t r o}$, which is a binary indicator that equals unity if a given county is classified as a metropolitan area according to the U.S. Department of

\footnotetext{
${ }^{17}$ The states are: Delaware, Massachusetts, Michigan, Missouri, Montana, Nevada, South Dakota, Wisconsin, and Wyoming.

${ }^{18} \mathrm{http} / / /$ gis.cdc.gov/GRASP/NCHHSTPAtlas/main.html accessed 2/19/15.
} 
Agriculture's Economic Research Services 1993 rural-urban continuum code classification. ${ }^{19}$ Auxiliary regressions examine the natural $\log$ of the teen birth rate (in year $t+1$ ), as well as the county gonorrhea rate (in year $t$ ) and the county abortion rate (in year $t$ ). As described above, the measure of broadband access, $B B p c t_{c t}$, is defined as the population-weighted percentage of zip codes in a given county with at least one broadband provider, the year before we observe the birth. In models without the interaction with $\mathrm{Metro}_{c}$, the coefficient of interest, $\beta_{1}$, is interpreted as the change in the teen birth (or gonorrhea or abortion) rate as broadband diffusion within a county increases from zero geographic coverage to full geographic coverage. In models with the interaction with Metro $_{c}, \beta_{1}$ captures the effect of broadband diffusion in all areas, and the $\beta_{2}$ indicates whether there is a differential effect of broadband availability in metro versus nonmetro areas. Identification comes from the differential timing in the introduction and subsequent expansion of broadband internet across counties.

The model also includes a rich set of observable county covariates, $X_{c t}$, as listed in the Data Sources section above. In addition, the model includes county fixed effects, $\gamma_{c}$, to absorb permanent unobserved county heterogeneity, year fixed effects, $\tau_{t}$, to absorb unobserved timevarying shocks, and county-specific linear time trends, $\delta_{c t}$, to control for unobservables that are differentially trending within counties. All regressions are weighted by the county population, and the standard errors are robust to heteroskedasticity and are clustered by county to account for possible serial correlation within each county. ${ }^{20}$

Our measure of broadband diffusion is not binary but instead represents the populationweighted percentage of a county with at least one broadband provider serving at least one

\footnotetext{
${ }^{19}$ Codes obtained from http://www.ers.usda.gov/data-products/rural-urban-continuum-codes on 4/10/14.

${ }^{20}$ Estimates from unweighted regressions produce similar coefficient estimates, though the unweighted estimates are less precisely estimated.
} 
customer. To interpret the regression estimates as causal, we must assume that the common trends assumption holds; that is, counties with and without broadband would have had similar trends in the teen birth rate if the diffusion of broadband had not occurred. For the full sample, this is difficult to examine directly, since some counties enter the study period with a provider presence that is already nontrivial. ${ }^{21} \mathrm{We}$ can, however, examine birth rate trends for a group of counties with very low penetration in $1999\left(\right.$ BBpct $\left._{1999}<0.10\right)$. We break this group of counties into those that subsequently have full provider presence by 2002 (BBpct $2002>0.98)$ and those that do not. These trends are presented in Appendix Figure 1. We find that prior to 1999, trends in the teen birth rate (Appendix Figure 1) are fairly similar until the fully treated counties begin to have a provider presence (after 1999), at which point the birth rate in these counties falls substantially below the birth rate in the untreated counties. ${ }^{22}$ A few years later (after 2005)—when most counties are fully or nearly fully treated - the birth rates are approximately equal once again. Although we cannot reproduce this graph for all counties in the estimation sample, these figures provide support for the idea that teen birth trends were evolving similarly prior to the proliferation of broadband. Since this may have occurred for some counties prior to 1999 , it is important to adjust for county-specific time trends in the main analysis.

In auxiliary analyses, we examine several teen outcomes at the state level, and employ a regression of the following form:

$$
Y_{s t}=\beta_{0}+\beta_{1} B B p c t_{s t}+\beta_{2} X_{s t}+\gamma_{s}+\tau_{t}+\delta_{s t}+\varepsilon_{s t}
$$

where $Y_{s t}$ is the state percentage of teens who are sexually active; the state percentage of teens who report using a method to prevent pregnancy at last intercourse; the state percentage of teens

\footnotetext{
${ }^{21}$ The FCC data we use is only available starting in 1999, so we are unable to observe the exact time when every county gets their first provider.

22 The figure looks very similar if we examine the natural log of the birth rate rather than the birth rate.
} 
who have ever had sex, or the state teen gonorrhea rate. Our measure of broadband access is $B B p c t_{s t}$, which is the population-weighted measure of the percentage of zip codes in a state with at least one broadband provider. We also include the state unemployment rate, $X_{s t}$, state and year fixed effects, $\gamma_{s}$ and $\tau_{t}$ respectively, as well as $\delta_{s t}$, state specific linear time trends in all specifications. Regressions are weighted by the state population.

\section{Results}

\section{Teen Births}

Tables 2 and 3 report the main fertility results. The former table reports results from models of the teen birth rate, while the latter reports results from the log of the teen birth rate. Columns (1) through (4) in each table show the full sample estimates, both with and without the interaction of BBpct and Metro included. Columns (3) and (4) should be considered the baseline noninteracted and interacted models, respectively, given that they include the full set of controls. Columns (5) and (6) estimate the model separately on the subset of non-metropolitan counties, while columns (7) and (8) estimate the model separately on the subset of metropolitan counties.

The estimates reported in columns (1) and (3) of Table 2 show that the level of the teen birth rate is negatively associated with the percentage of the county with at least one broadband provider; as the percentage of a county with broadband access rises from zero to 100 percent we expect the teen birth rate to decline between 2.8 and 3.4 births per 1,000 teens ages 15 to 19 . This corresponds to a reduction of approximately 5.5 percent. In our county sample, the teen birth rate dropped from an average of 51.65 to an average of 46.83 births per 1,000 teens throughout the study period. The full model estimate in column (1), the smallest estimate, therefore implies that at least 13 percent of the decline in teen births between 1999 and 2007 can be explained by the 
increase in broadband internet access. ${ }^{23}$ In Table 3, we examine whether the results are robust to specifying the outcome variable as a logarithmic function. The estimates suggest that the drop in the teen birth rate is similar, although some statistical significance is lost.

The models in columns (2) and (4) as well as columns (5) through (8) allow the impact of broadband availability to vary across metropolitan and non-metropolitan counties. The full sample estimates that include BBpct-Metro interactions [columns (2) and (4)] are similar in size to the full sample estimates that exclude these interactions [columns (1) and (3)]. This suggests that the average effect in the sample is not different for the metro areas. Examining each area separately, we see that although there might be small drops in the teen birth rate in rural areas [columns (5) and (6)], these estimates are not statistically significant. It is in the urban areas where the most dramatic drops in teen birth rates are observed [columns (7) and (8)].

One concern is that even with the rich set of observable covariates included in the regression (as well as county and year effects) we may still be estimating a spurious relationship between teen births and broadband. If so, then we should find similar estimates when examining teen births from a slightly earlier period, since teen births have been declining at a fairly steady rate since the early 1990s. To explore this possibility, we conduct a type of falsification test in which we examine the relationship between teen birth rates lagged three years and the current year BBpct using a model similar to our main specification:

$$
Y_{c t-3}=\beta_{0}+\beta_{1} B B p c t_{c t}+\gamma_{c}+\tau_{t-4}+\delta_{c t-4}+\varepsilon_{c t}
$$

For these regressions, the analysis sample is somewhat reduced relative to our main analysis sample (see Table 2) since some counties in our original sample do not have teen birth information for the mid-1990s. These results are presented in Panel A of Appendix Table 1. Results in columns

\footnotetext{
${ }^{23}$ The percentage of broadband providers in a county increased by around 0.23 over the period. Therefore: $(0.23) *(-2.8) /(51.65-$ $46.83)=13.3 \%$. The estimate in column (4) suggests a decrease of $17 \%$.
} 
(1) to (4) come from models estimated over the period 1999 to 2003, and those in columns (5) to

(8) represent the full study period, 1999 to 2007. First, we see current year BBpct has no statistically significant impact on a three year lag of the teen birth rate in any of the specifications. Second, the magnitude of the estimates for the lagged teen birth rate is small, especially in the earlier period.

Next, we compare the results in Panel A with estimates obtained using the same model, except that the dependent variable is the teen birth rate in year $t+1$, which is identical to the definition used in the main analysis (Table 2). Panel B of Appendix Table 1 contains these estimates. Columns (5) and (6) of Panel B, which are comparable to columns (1) and (2) of Table 2, produce similar estimates even though the analysis sample is slightly different. Finally, if we compare Panel A with Panel B estimates, we see that Panel A estimates are generally smaller (in both time periods) and never statistically significant, while Panel B estimates reveal a negative relationship (in both time periods) between broadband access and the teen birth rate. Together, this exercise suggests that our results are not simply picking up a spurious correlation between broadband and teen births, but instead indicate that teen birth rates actually decline as counties adopt broadband. Next, we explore possible mechanisms for the observed drop in births.

\section{Teen Risky Behaviors}

We examine teen risky behaviors at the county level (Tables 4 and 5) and at the state level (Table 6). In Table 4, we examine whether teen abortion rates changed in response to broadband diffusion. The coefficient estimates are generally positive but not statistically significant and fairly small in magnitude. Additionally, estimates for non-metro counties are closer to zero than metro counties. The estimates, however, do not provide us with evidence of a statistically significant relationship in either direction. One drawback of the county abortion rates is that they are not 
specifically teen abortion rates. This measurement error may attenuate estimates of the true relationship between broadband access and teen abortions.

Table 5 reports estimates of the relationship between the county gonorrhea rate (number of cases per 100,000 individuals in the county) and broadband access. The coefficients are generally negative, but also statistically insignificant except for the main effect for the full sample, which implies gonorrhea rates fell with the roll-out of broadband. The estimates for non-metro [columns (5) and (6)] versus metro [columns (7) and (8)] suggest that this might be driven by drops in nonmetro counties. Overall, these estimates provide some evidence of a decline in the incidence of sexually transmitted infections (STIs) over the period 1999 to 2007, although we are cautious in interpreting it as such given the marginal statistical significance of the estimates. Assuming there is a drop in STIs, it could be due to a drop in sexual activity or an increase in the use of methods of contraception that also deter STIs or both, which we examine in our state level analysis.

We further explore teen risky behavior using data available at the state level and present these estimates in Table 6. The first six columns utilize the YRBS data to examine whether a teen is currently sexually active [columns (1) and (2)], has ever had sex [columns (3) and (4)], and if sexually active whether contraception was used at last sex [columns (5) and (6)]. These estimates suggest that increasing broadband access decreases the percentage of teens considered sexually active or who have ever had sex, although the results are not statistically significant. The estimates for whether a teen used a method at last sex to prevent pregnancy, conditional on being sexual active are marginally statistically significant and imply that broadband access is positively related to use of a method at last sex. Next, we see that estimates for state teen gonorrhea rates [columns (7) and (8)] are negatively signed (like the county gonorrhea estimates) but that they are statistically insignificant. Overall, although the estimates in Table 6 are generally not statistically 
significant, the signs of the coefficients are consistent with increases in broadband access decreasing rates of sexual activity, increasing contraceptive use, and lowering the probability of ever having sex.

\section{Discussion and Conclusion}

The decline in the U.S. teen birth rate has continued virtually unabated since the early1990s. As a result, investigations such as that conducted by Kearney and Levine (2012) attempt to understand the factors underlying this dramatic decline. Although Kearney and Levine (2012) note that the reduction is explained in equal parts by a decline in teen sexual activity and the increased use of contraception, it remains unclear as to what is driving these emerging teen behaviors. This paper proposes and tests a novel explanation for the reduction in the teen birth rate: the rapid diffusion of high-speed broadband internet.

At the start of the $21^{\text {st }}$ century, broadband internet was used by a very small number of U.S. households. Today, however, such an internet connection is the norm within most homes. Broadband internet has the potential to shape in powerful ways the nature and intensity of individuals' social connections as well as the quantity and quality of information received on relationships and sexual health. Indeed, as shown in Figures 2a to 2f, Americans are increasingly turning to the internet for a wide range of advice on romantic relationships, sex, and contraceptive methods. These figures show the volume of U.S. Google searches between (January) 2004 and (January) 2014 that contain various phrases. Americans-including teens-are asking for guidance on everything from whether they should have sex with a certain individual and the most effective forms of contraception to how to deal with a cheating boyfriend. Teens, who now spend more time engaging with various forms of media - much of it on-line - than any other activity 
(aside from sleep) (Rideout et al., 2010), are particularly well-positioned to take advantage of new information and relationship landscape created by explosion in broadband internet.

The purpose of this study is to examine whether increases in the number of broadband providers influences teen fertility. We posit that the increased availability of information influenced the teen birth rate, but in a potentially ambiguous direction. Our empirical analysis suggest that teen birth rates declined with the greater access to information due to broadband access and our estimates suggest that at least thirteen percent of the total decline in the teen birth rate between 1999 and 2007 can be explained by increases in high-speed internet access. We hypothesize that a decline in births could be due to decreases in sexual activity, increases in contraception, or both. Although the evidence on risky behavior is too weak to draw definitive conclusions, the estimates are consistent with decreases in sexual activity as well as increases in contraceptive use (among the sexually active), both of which are supported by the estimated reduction in STIs. We do not find evidence that broadband access lead to changes in abortion, which may reflect in part the fact that the count of abortions includes all individuals, including non-teens, which makes it a noisy measure of teen activity.

Our results are congruent with the other recent studies on the teen fertility effects of new media. Levine and Kearney (2014), for example, find that the MTV show 16 and Pregnant led to a 5.7 percent decline in teen births in the 18 months after the show's debut. Our results suggest a smaller effect, approximately 1.5 percent over eight years, but show that the effects of new media are present during an intermediate period of the growth in access to digital media in the U.S. Additionally, although not tested in this paper, we suggest that access to the internet through even slow-speed connections during the 1990s may have had a dampening effect on teen fertility. 


\section{References}

Akerman, Anders, Ingvil Gaarder, and Magne Mogstad, 2013. "The Skill Complementarity of Broadband Internet," IZA Working Paper No. 7762, http://ftp.iza.org/dp7762.pdf.

Atasoy, H. (2013). The effects of broadband internet expansion on labor market outcomes. Industrial and Labor Relations Review, 66, 315-345.

Bhargava, S. \& Pathania, V. (2013). Driving under the (Cellular) Influence. American Economic Journal: Economic Policy, 5, 92-125.

Dahl, G. \& DellaVigna, S. (2009). Does movie violence increase violent crime? Quarterly Journal of Economics, 124, 677-734.

Dahl, G. \& Price, J. (2012). The Economists Approach to Studying the Impact of Media on the Family. Family Relations, 61, 363-373.

Dettling, Lisa J. (2014). Broadband in the Labor Market: The Impact of Residential High Speed Internet on Married Women's Labor Force Participation Mimeo, http://econweb.umd.edu/ dettling/dettling_internet.pdf downloaded on 12-12-14.

Horrigan, J. (2009). Home Broadband Adoption 2009. Pew Research Center. Washington, DC: Pew Research Center.

Jensen, R. \& Oster, E. (2009). The Power of TV: Cable Television and Women's Status in India. The Quarterly Journal of Economics, 124, 1057-109.

Kane, T. \& Staiger, D. (1996). Teen motherhood and abortion access. Quarterly Journal of Economics, 111, 467-506.

Kolko, J. (2012). Broadband and local growth. Journal of Urban Economics, 71, 100-113.

La Ferrara, E., Chong, A., \& Duryea, S. (2012). Soap Operas and Fertility: Evidence from Brazil. American Economic Journal: Applied Economics, 4, 1-31.

Lenhart, A. (2012a). Teens, Smartphones and Texting. Pew Research Center. Washington, DC: Pew Research Center.

Lenhart, A. (2012b). Teens and Online Video. Pew Research Center. Washington, DC: Pew Research Center.

Levine, P. B. (2004). Sex and consequences: Abortion, public policy, and the economics of fertility. Princeton, NJ: Princeton University Press. 
Levine, P.B. \& Kearney, M. (2014). Media influences on social outcomes: The impact of MTV's 16 and Pregnant on teen childbearing. NBER Working Paper No. 19795. Cambridge, MA: National Bureau of Economic Research.

Madden, M., Lenhart, A., Duggan, M., Cortesi, S., \& Gasser, U. (2013). Teens and Technology 2013. Pew Research Center. Washington, DC: Pew Research Center.

National Telecommunications and Information Administration. (2013). Exploring the Digital Nation: America's Emerging Online Experience. Washington, DC: U.S. Department of Commerce.

Olken, B. (2009). Do TV and Radio Destroy Social Capital? Evidence from Indonesian Villages. American Economic Journal: Applied Economics, 1, 1-33.

Palsson, C. (2014). That Smarts!: Smartphones and Child Injuries. Working Paper. Department of Economics, Yale University. New Haven, CT: Yale University.

Redelmeier, D. \& Tibshirani, R. (1997). Association between Cellular-Telephone Calls and Motor Vehicle Collisions. New England Journal of Medicine, 336, 453-458.

Rideout, V., Foehr, U., \& Roberts, D., (2010). Generation $\mathrm{M}^{2}$ : Media in the Lives of 8- to 18-YearOlds. The Henry J. Kaiser Family Foundation. Menlo Park, CA: Kaiser Family Foundation.

Temple, J., Paul, J., van den Berg, P., Le, V., McElhany, A., \& Temple, B. (2012). Teen sexting and its association with sexual behaviors. Arch Pediatr Adolesc Med, 166, 828-833.

The National Campaign to Prevent Teen Pregnancy and Unplanned Parenthood. (2008). Sex and Tech: Results from a Survey of Teens and Young Adults. Washington, DC: The National Campaign.

Trudeau, Jennifer. (2014). The Role of New Media on Teen Sexual Behaviors and Fertility Outcomes - The Case of '16 and Pregnant'. Unpublished Manuscript.

U.S. Census Bureau, Current Population Survey, October 1984, 1989, 1993, 1997, 2000, 2001, 2003, 2007, 2009. http://www.census.gov/hhes/computer/files/Appendix-TableA.xls.

U.S. Department of Commerce "Exploring the Digital Nation: Computer and Internet Use at Home", November 2011.

Zickuhr, K. \& Smith, A. (2013). Home Broadband 2013. Pew Research Center. Washington, DC: Pew Research Center. 
Figure 1: County Teen Birth Rates and Percentage of Counties with One or More Broadband Provider, 1999-2007

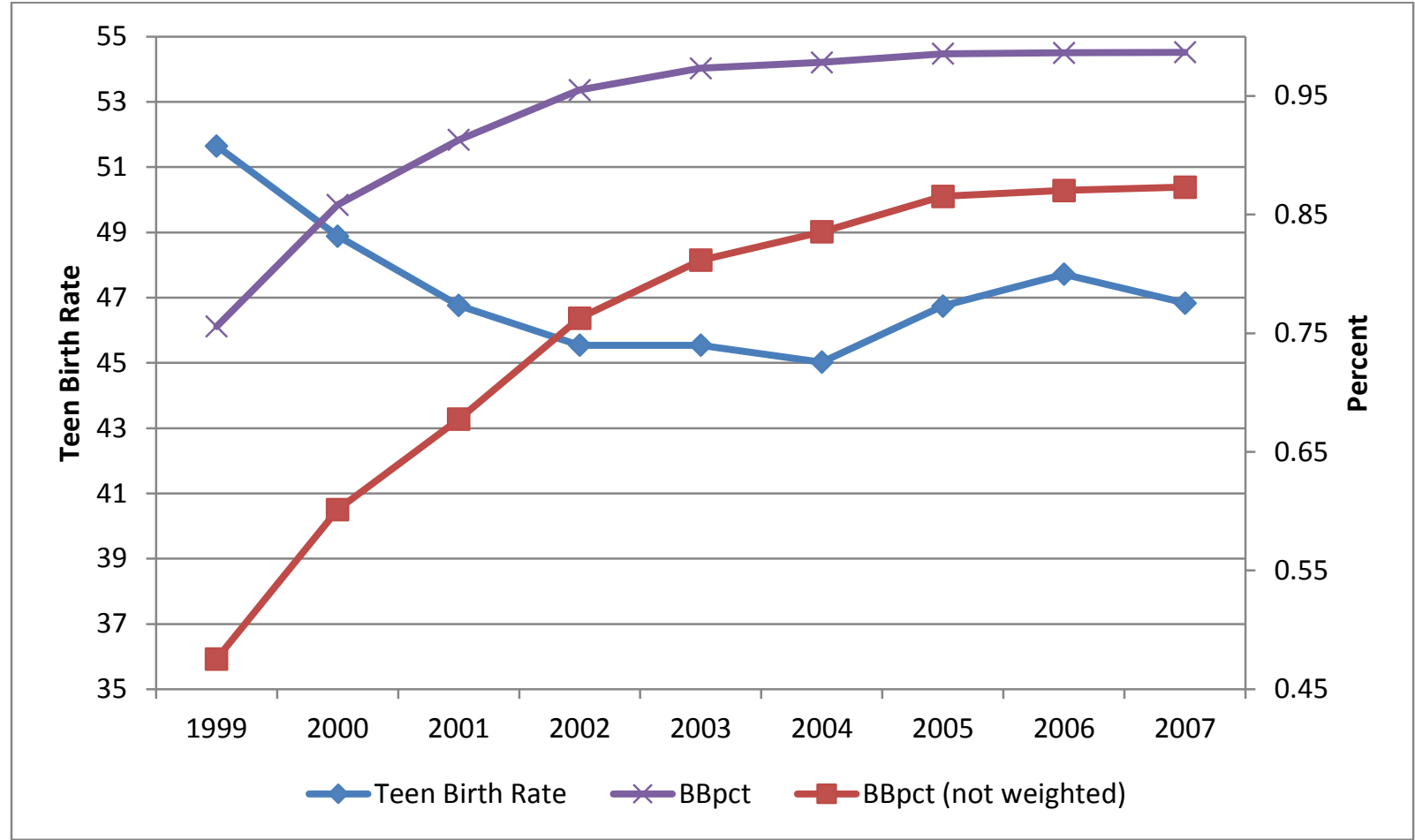

Source of Broadband access at County level (BBpct): Authors' computations using the FCC's form 477 data. BBpct is the percentage of a county with at least one broadband provider, where the percentage is created by weighting each zip code's provider presence by the zip code population. The unweighted BBpct measure is similar except each zip code is equally weighted in the computation. This is described in more detail in the text. The zip codes that do not appear in the FCC data are assumed to have zero providers. The county is assumed to have a provider if at least one zip code in the county reports having a provider. Source of Teen Birth Rates: National Vital Statistics Annual Reports 
Figure 2a: U.S. Google Searches for "should i have sex...”, 2004-2014

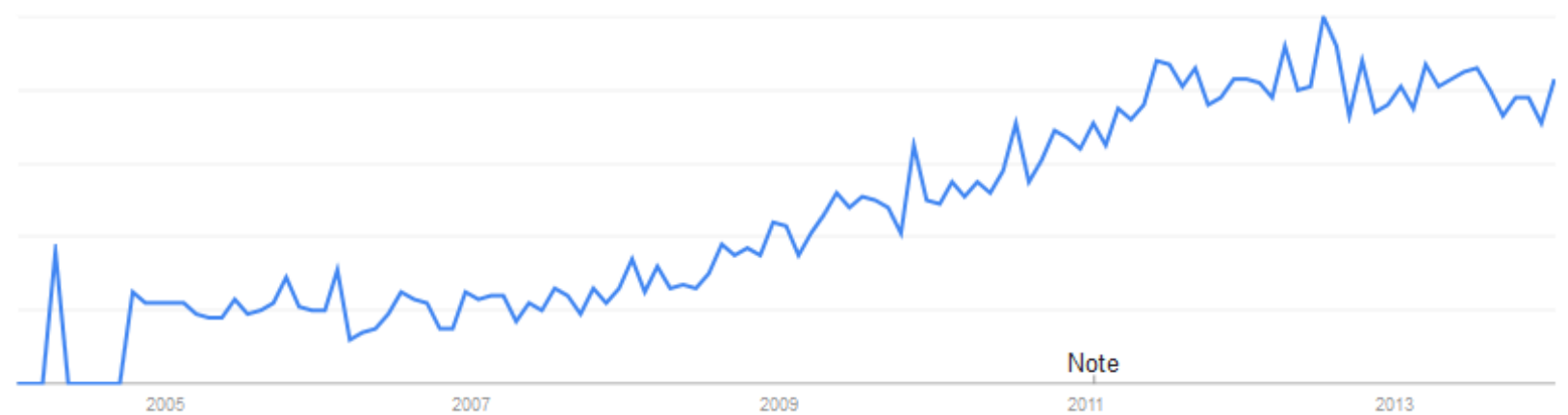

Figure 2b: U.S. Google Searches for “does the pill...”, 2004-2014

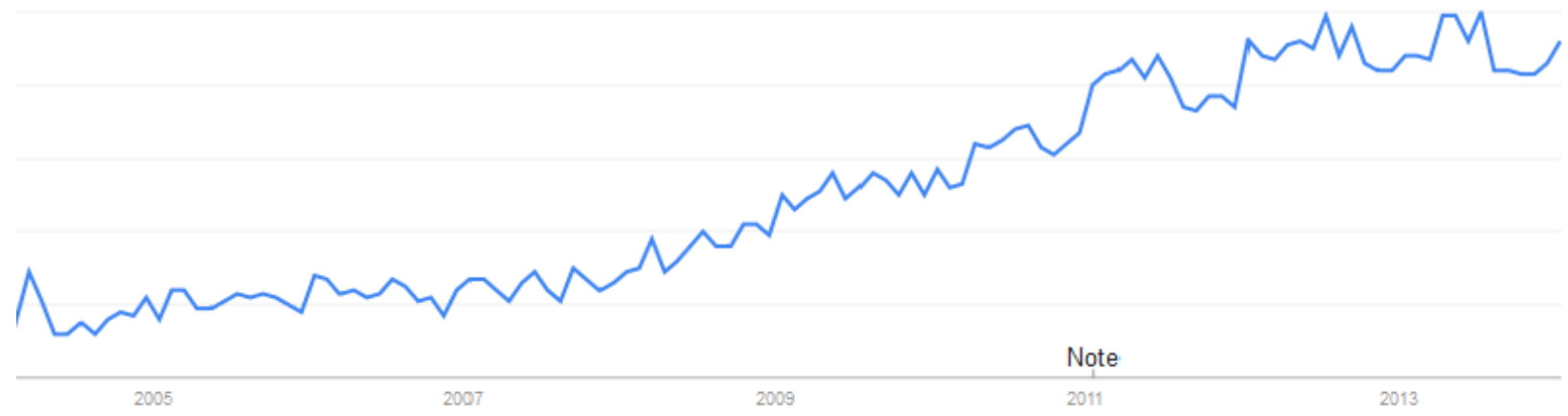

Figure 2c: U.S. Google Searches for “best condoms”, 2004-2014

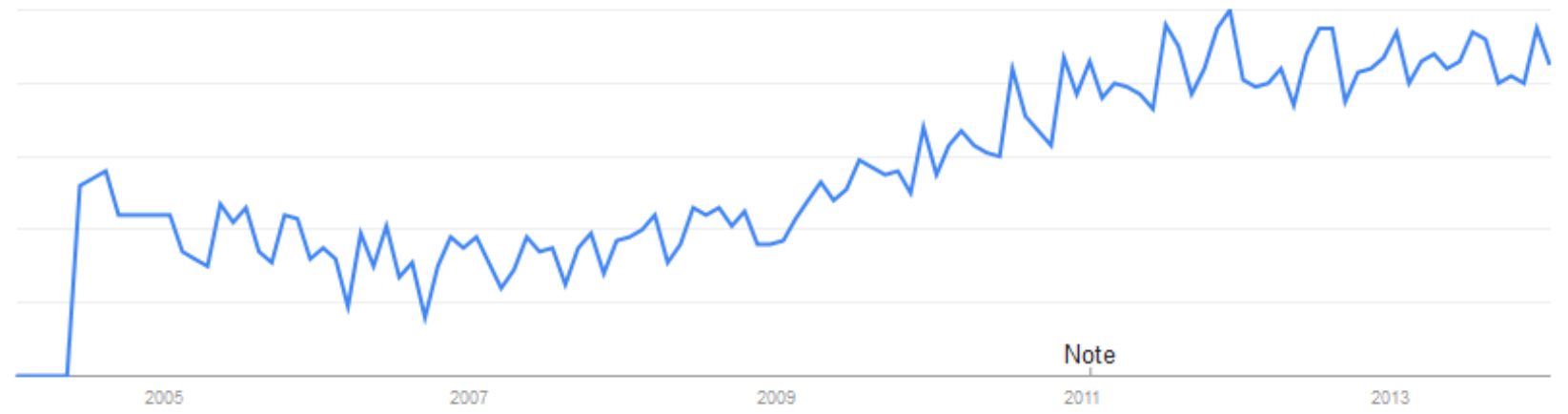


Figure 2d: U.S. Google Searches for “does sex cause...”, 2004-2014

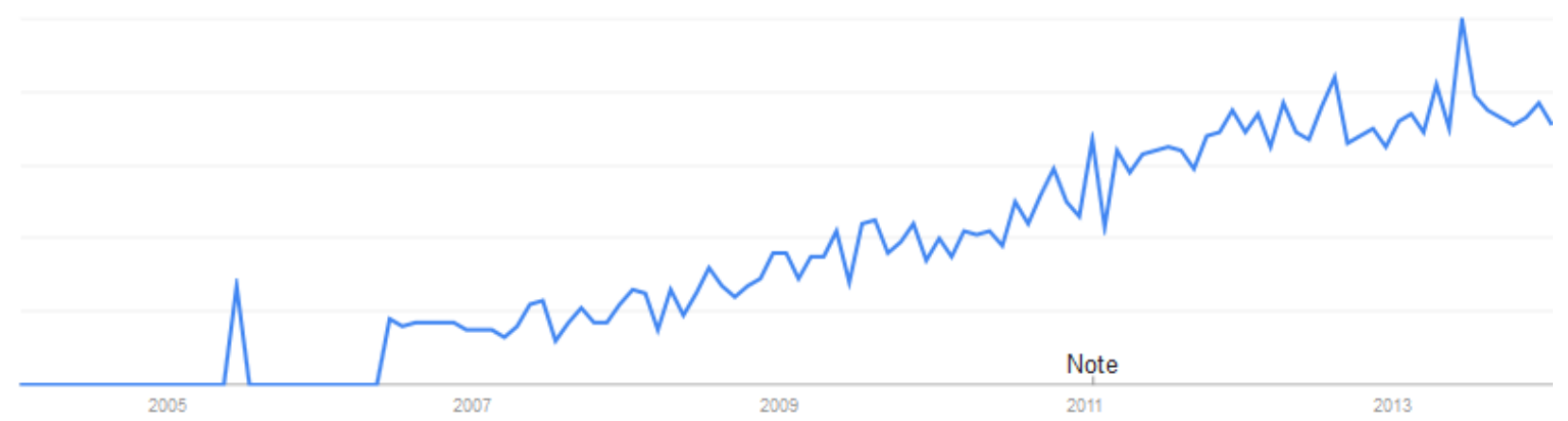

Figure 2e: U.S. Google Searches for “will i get pregnant...”, 2004-2014

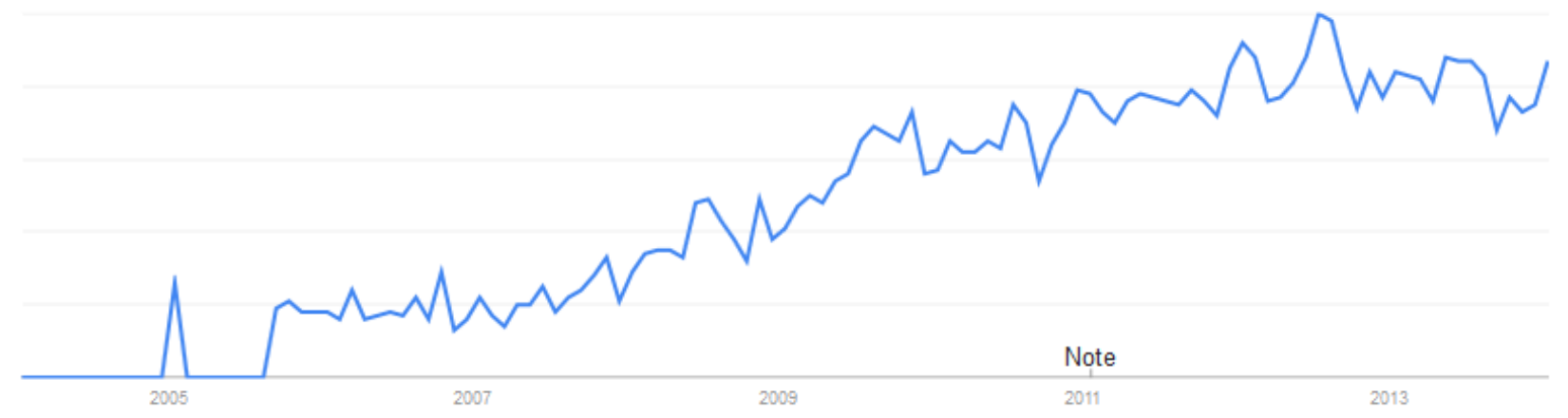

Figure 2f: U.S. Google Searches for "boyfriend cheating", 2004-2014

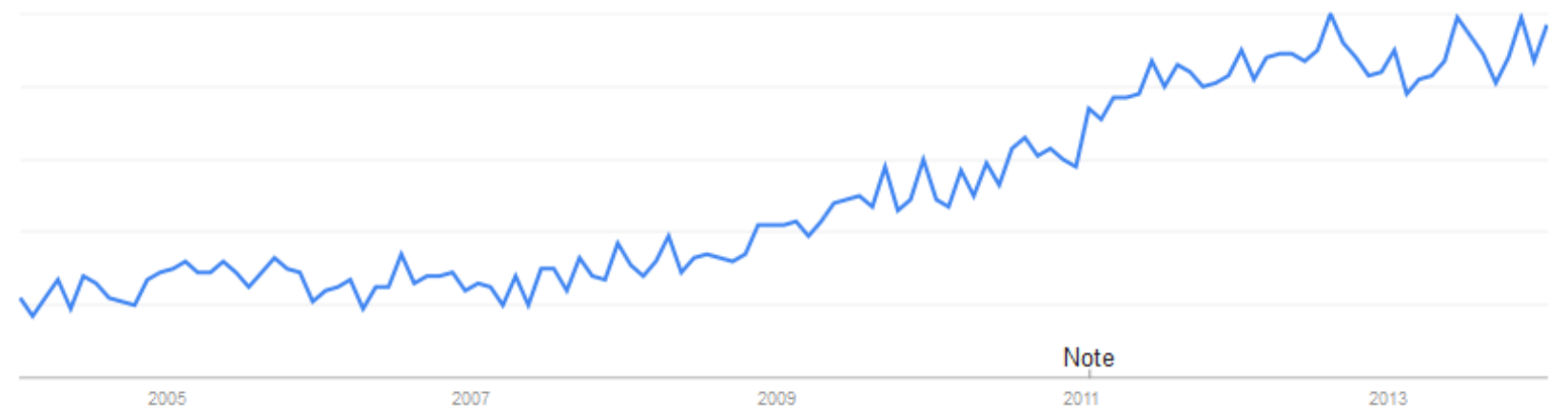


Table 1: Summary Statistics

\begin{tabular}{lrrrrr}
\hline Variable & Mean & Std. Dev. & Min & Max & N \\
\hline Panel A: County Level Data & & & & & \\
BBPCT & 0.93 & 0.15 & 0 & 1 & 22824 \\
Teen Birth Rate & 47.17 & 21.46 & 2.21 & 172.16 & 22824 \\
ln(Teen Birth Rate) & 3.74 & 0.52 & 0.79 & 5.15 & 22824 \\
Gonorrhea Rate & 90.13 & 107.29 & 1.11 & 1198.81 & 8894 \\
Abortion Rate & 3.49 & 3.57 & 0 & 98.35 & 13858 \\
& & & & & \\
Panel B: State Level Data & & & & & \\
Ever Had Sex & 46.15 & 5.13 & 36.83 & 59.32 & 45 \\
Method Used at Last Sex & 88.52 & 1.99 & 84.51 & 94.13 & 44 \\
Sexually Active & 33.41 & 4.23 & 26.55 & 45.34 & 45 \\
Teen Gonorrhea Rate & 416.60 & 363.67 & 6.4 & 2510.6 & 392 \\
\hline
\end{tabular}


Table 2: Estimates of the Impact of Broadband Diffusion on the Teen Birth Rate

\begin{tabular}{|c|c|c|c|c|c|c|c|c|}
\hline & $(1)$ & $(2)$ & (3) & $(4)$ & (5) & (6) & (7) & $(8)$ \\
\hline ВBPCT & $\begin{array}{l}-2.8143 * * * \\
(0.857)\end{array}$ & $\begin{array}{l}-3.1717 * * * \\
(0.916)\end{array}$ & $\begin{array}{l}-3.4353 * * * \\
(0.878)\end{array}$ & $\begin{array}{l}-3.5743 * * * \\
(0.947)\end{array}$ & $\begin{array}{c}-0.0818 \\
(0.986)\end{array}$ & $\begin{array}{c}-0.3690 \\
(0.997)\end{array}$ & $\begin{array}{c}-2.8199 \\
(1.873)\end{array}$ & $\begin{array}{l}-5.1892 * * * \\
(1.897)\end{array}$ \\
\hline BBPCT*METRO & & $\begin{array}{r}1.8209 \\
(1.931)\end{array}$ & & $\begin{array}{c}0.6996 \\
(1.970)\end{array}$ & & & & \\
\hline Estimation sample & Full & Full & Full & Full & Non-Metro & Non-Metro & Metro & Metro \\
\hline County fixed effects & $\mathrm{x}$ & $\mathrm{x}$ & $\mathrm{x}$ & $\mathrm{x}$ & $\mathrm{x}$ & $\mathrm{x}$ & $\mathrm{x}$ & $\mathrm{x}$ \\
\hline Year fixed effects & $\mathrm{x}$ & $\mathrm{x}$ & $\mathrm{x}$ & $\mathrm{x}$ & $\mathrm{x}$ & $\mathrm{x}$ & $\mathrm{x}$ & $\mathrm{x}$ \\
\hline County linear trends & $\mathrm{x}$ & $\mathrm{x}$ & $\mathrm{x}$ & $\mathrm{x}$ & $\mathrm{x}$ & $\mathrm{x}$ & $\mathrm{x}$ & $\mathrm{x}$ \\
\hline County covariates & & & $\mathrm{x}$ & $\mathrm{x}$ & & $\mathrm{x}$ & & $\mathrm{x}$ \\
\hline Observations & 22,824 & 22,824 & 22,257 & 22,257 & 15,616 & 15,311 & 7,208 & 6,946 \\
\hline
\end{tabular}

Notes: Robust standard errors clustered by county to account for possible serial correlation in parenthesis, $* * *$ p $<0.01$. All regressions are weighted by the total county population

(SEER). The dependent variable is the teen birth rate, which is the number of births to teens aged 15 to 19 divided by the population of female teens aged 15 to 19 in the county of interest. BBPCT is the percentage of county zip codes that has a provider. METRO is an indicator equal to one if the county is classified as a metropolitan county according to the USDA's 1993 rural-urban continuum. The County covariates include the population density, the unemployment rate, the county personal income per capita, the percentage white, the percentage Hispanic, the percentage of the population with a BA degree, and county-by-year expenditure Medicaid, Supplemental Security Income (SSI), Temporary

Assistance to Needy Families (TANF), Supplemental Nutritional Assistance Program (SNAP), and a summary measure of county expenditures on the Earned Income Tax Credit, the Women, Infant, and Children Program, and the Child Tax Credit. Louisiana and Hawaii are omitted from the analysis. 
Table 3: Estimates of the Impact of Broadband Diffusion on the Natural Log of the Teen Birth Rate

\begin{tabular}{|c|c|c|c|c|c|c|c|c|}
\hline & $(1)$ & $(2)$ & (3) & (4) & $(5)$ & (6) & $(7)$ & $(8)$ \\
\hline BBPCT & $\begin{array}{c}-0.0284 \\
(0.020)\end{array}$ & $\begin{array}{c}-0.0369 * \\
(0.020)\end{array}$ & $\begin{array}{l}-0.0412 * * \\
(0.020)\end{array}$ & $\begin{array}{l}-0.0470 * * \\
(0.021)\end{array}$ & $\begin{array}{l}0.0079 \\
(0.022)\end{array}$ & $\begin{array}{l}-0.0005 \\
(0.022)\end{array}$ & $\begin{array}{c}-0.0133 \\
(0.046)\end{array}$ & $\begin{array}{r}-0.0472 \\
(0.047)\end{array}$ \\
\hline BBPCT*METRO & & $\begin{array}{r}0.0432 \\
(0.046) \\
\end{array}$ & & $\begin{array}{c}0.0294 \\
(0.047) \\
\end{array}$ & & & & \\
\hline Estimation sample & Full & Full & Full & Full & Non-Metro & Non-Metro & Metro & Metro \\
\hline County fixed effects & $\mathrm{x}$ & $\mathrm{x}$ & $\mathrm{x}$ & $\mathrm{x}$ & $\mathrm{x}$ & $\mathrm{x}$ & $\mathrm{x}$ & $\mathrm{x}$ \\
\hline Year fixed effects & $\mathrm{x}$ & $\mathrm{x}$ & $\mathrm{x}$ & $\mathrm{x}$ & $\mathrm{x}$ & $\mathrm{x}$ & $\mathrm{x}$ & $\mathrm{x}$ \\
\hline County linear trends & $\mathrm{x}$ & $\mathrm{x}$ & $\mathrm{x}$ & $\mathrm{x}$ & $\mathrm{x}$ & $\mathrm{x}$ & $\mathrm{x}$ & $\mathrm{x}$ \\
\hline County covariates & & & $\mathrm{x}$ & $\mathrm{x}$ & & $\mathrm{x}$ & & $\mathrm{x}$ \\
\hline Observations & 22,824 & 22,824 & 22,257 & 22,257 & 15,616 & 15,311 & 7,208 & 6,946 \\
\hline
\end{tabular}

Notes: Robust standard errors clustered by county to account for possible serial correlation in parenthesis, $* *$ p $<0.05$. All regressions are weighted by the total county population (SEER). The dependent variable is the natural log of the teen birth rate, which is the number of births to teens aged 15 to 19 divided by the population of female teens aged 15 to 19 in the county of interest. BBPCT is the population weighted percentage of county zip codes that has a provider. METRO is an indicator equal to one if the county is classified as a metropolitan county according to the USDA's 1993 rural-urban continuum. The County covariates include the population density, the unemployment rate, the county personal income per capita, the percentage white, the percentage Hispanic, the percentage of the population with a BA degree, and county-by-year expenditure Medicaid, Supplemental Security Income (SSI), Temporary Assistance to Needy Families (TANF), Supplemental Nutritional Assistance Program (SNAP) and), and a summary measure of county expenditures on the Earned Income Tax Credit, the Women, Infant, and Children Program, and the Child Tax Credit. Louisiana and Hawaii are omitted from the analysis. 
Table 4: Estimates of the Impact of Broadband Diffusion on the Abortion Rate

\begin{tabular}{|c|c|c|c|c|c|c|c|c|}
\hline & (1) & (2) & (3) & (4) & (5) & (6) & (7) & (8) \\
\hline \multirow[t]{2}{*}{ BBPCT } & 0.2990 & 0.2705 & 0.0916 & 0.0592 & 0.0038 & -0.0561 & 0.4601 & 0.2182 \\
\hline & $(0.206)$ & $(0.196)$ & $(0.214)$ & $(0.211)$ & $(0.145)$ & $(0.143)$ & $(0.507)$ & $(0.524)$ \\
\hline \multirow[t]{2}{*}{ BBPCT*METRO } & & 0.1381 & & 0.1567 & & & & \\
\hline & & $(0.436)$ & & $(0.429)$ & & & & \\
\hline Estimation sample & Full & Full & Full & Full & Non-Metro & Non-Metro & Metro & Metro \\
\hline County fixed effects & $\mathrm{x}$ & $\mathrm{x}$ & $\mathrm{x}$ & $\mathrm{x}$ & $\mathrm{x}$ & $\mathrm{x}$ & $\mathrm{x}$ & $\mathrm{x}$ \\
\hline Year fixed effects & $\mathrm{x}$ & $\mathrm{x}$ & $\mathrm{x}$ & $\mathrm{x}$ & $\mathrm{x}$ & $\mathrm{x}$ & $\mathrm{x}$ & $\mathrm{x}$ \\
\hline County covariates & & & $\mathrm{x}$ & $\mathrm{x}$ & & $\mathrm{x}$ & & $\mathrm{x}$ \\
\hline Observations & 16,821 & 16,821 & 16,332 & 16,332 & 11,205 & 10,962 & 5,616 & 5,370 \\
\hline
\end{tabular}

Notes: Robust standard errors are clustered by county to account for possible serial correlation. All regressions are weighted by the total county population (SEER). The dependent variable is the county abortion rate (number of abortions per 1000 women) for the 33 states with county information over the period 1999 to 2007 . BBPCT is the population weighted percentage of county zip codes that has a provider. METRO is an indicator equal to one if the county is classified as a metropolitan county according to the USDA's 1993 rural-urban continuum. The County covariates include the population density, the unemployment rate, the county personal income per capita, the percentage white, the percentage Hispanic, the percentage of the population with a BA degree, and county-by-year expenditure Medicaid, Supplemental Security Income (SSI), Temporary Assistance to Needy Families (TANF), Supplemental Nutritional Assistance Program (SNAP) and), and a summary measure of county expenditure on the Earned Income Tax Credit, the Women, Infant, and Children Program, and the Child Tax Credit. 
Table 5: Estimates of the Impact of Broadband Diffusion on the Gonorrhea Rate, 1999-2007

\begin{tabular}{|c|c|c|c|c|c|c|c|c|}
\hline & $(1)$ & $(2)$ & (3) & (4) & $(5)$ & (6) & $(7)$ & $(8)$ \\
\hline BBPCT & $\begin{array}{l}3.9531 \\
(13.725)\end{array}$ & $\begin{array}{l}-4.3947 \\
(10.816)\end{array}$ & $\begin{array}{l}-11.4695 \\
(12.868)\end{array}$ & $\begin{array}{l}-18.4810 * \\
(10.865)\end{array}$ & $\begin{array}{l}-6.4524 \\
(8.303)\end{array}$ & $\begin{array}{l}-3.6238 \\
(8.666)\end{array}$ & $\begin{array}{l}25.6687 \\
(35.126)\end{array}$ & $\begin{array}{l}-3.3546 \\
(33.024)\end{array}$ \\
\hline BBPCT*METRO & & $\begin{array}{r}31.7010 \\
(31.849)\end{array}$ & & $\begin{array}{r}26.2787 \\
(30.483)\end{array}$ & & & & \\
\hline Estimation sample & Full & Full & Full & Full & Non-Metro & Non-Metro & Metro & Metro \\
\hline County fixed effects & $\mathrm{x}$ & $\mathrm{x}$ & $\mathrm{x}$ & $\mathrm{x}$ & $\mathrm{x}$ & $\mathrm{x}$ & $\mathrm{x}$ & $\mathrm{x}$ \\
\hline Year fixed effects & $\mathrm{x}$ & $\mathrm{x}$ & $\mathrm{x}$ & $\mathrm{x}$ & $\mathrm{x}$ & $\mathrm{x}$ & $\mathrm{x}$ & $\mathrm{x}$ \\
\hline County linear trends & $\mathrm{x}$ & $\mathrm{x}$ & $\mathrm{x}$ & $\mathrm{x}$ & $\mathrm{x}$ & $\mathrm{x}$ & $\mathrm{x}$ & $\mathrm{x}$ \\
\hline County covariates & & & $\mathrm{x}$ & $\mathrm{x}$ & & $\mathrm{x}$ & & $\mathrm{x}$ \\
\hline Observations & 8,894 & 8,894 & 8,537 & 8,537 & 5,130 & 4,992 & 3,764 & 3,545 \\
\hline
\end{tabular}

Notes: Standard errors are clustered by county to account for possible serial correlation in parenthesis, * p $<0.10$. All regressions are weighted by the total county population

(SEER). The dependent variable is the county gonorrhea rate (cases per 100,000 of county population) as computed by the Center for Disease Control (CDC) for the counties in the 30 states reporting county information to the CDC from 1999 to 2007. BBPCT is the population weighted percentage of county zip codes that has a provider. METRO is an indicator equal to one if the county is classified as a metropolitan county according to the USDA's 1993 rural-urban continuum. The County covariates include the population density, the unemployment rate, the county personal income per capita, the percentage white, the percentage Hispanic, the percentage of the population with a BA degree, and county-by-year expenditure Medicaid, Supplemental Security Income (SSI), Temporary Assistance to Needy Families (TANF), Supplemental Nutritional Assistance Program (SNAP) and), and a summary measure of county expenditure on the Earned Income Tax Credit, the Women, Infant, and Children Program, and the Child Tax Credit. 
Table 6: State Level Teen Risky Behavior, 1999-2007

\begin{tabular}{|c|c|c|c|c|c|c|c|c|}
\hline & (1) & (2) & (3) & (4) & (5) & (6) & (7) & $(8)$ \\
\hline BBPCT & $\begin{array}{l}-27.3921 \\
(15.272)\end{array}$ & $\begin{array}{l}-21.9206 \\
(13.931)\end{array}$ & $\begin{array}{l}-27.3921 \\
(15.272)\end{array}$ & $\begin{array}{l}-21.9206 \\
(13.931)\end{array}$ & $\begin{array}{c}41.9127^{*} \\
(18.693)\end{array}$ & $\begin{array}{c}53.1208 * * \\
(22.762)\end{array}$ & $\begin{array}{r}-460.5060 \\
(642.895)\end{array}$ & $\begin{array}{r}-490.3434 \\
(659.348)\end{array}$ \\
\hline Outcome variable & \multicolumn{2}{|c|}{ Sexually Active $^{\mathrm{a}}$} & \multicolumn{2}{|c|}{ Ever Had Sex ${ }^{a}$} & \multicolumn{2}{|c|}{ Method at Last Sex ${ }^{a}$} & \multicolumn{2}{|c|}{ Teen Gonorrhea Rate ${ }^{b}$} \\
\hline Observations & 45 & 45 & 45 & 45 & 44 & 44 & 392 & 392 \\
\hline State fixed effects & $\mathrm{x}$ & $\mathrm{x}$ & $\mathrm{x}$ & $\mathrm{x}$ & $\mathrm{x}$ & $\mathrm{x}$ & $\mathrm{x}$ & $\mathrm{x}$ \\
\hline Year fixed effects & $\mathrm{x}$ & $\mathrm{x}$ & $\mathrm{x}$ & $\mathrm{x}$ & $\mathrm{x}$ & $\mathrm{x}$ & $\mathrm{x}$ & $\mathrm{x}$ \\
\hline State linear trends & $\mathrm{x}$ & $\mathrm{x}$ & $\mathrm{x}$ & $\mathrm{x}$ & $\mathrm{x}$ & $\mathrm{x}$ & $\mathrm{x}$ & $\mathrm{x}$ \\
\hline Unemployment rate & & $\mathrm{x}$ & & $\mathrm{x}$ & & $\mathrm{x}$ & & $\mathrm{x}$ \\
\hline
\end{tabular}

Sources: $a$. Youth Risk Behavior Surveillance System; Years: 1999, 2001, 2003, 2005, 2007; States: Delaware, Massachusetts, Michigan, Missouri, Montana, Nevada, South Dakota, Wisconsin, Wyoming. The responses are the percentage of respondents who report in the affirmative.

$b$. Teen Gonorrhea cases, 2000-2007, were obtained from CDC Atlas on 2/19/15. Thirty states had information for all years over the period.

Note: In all regressions, standard errors are clustered by state to account for possible serial correlation and are weighted by the total state population (SEER). The dependent variable is noted in the column header. BBPCT is the population weighted percentage of state zip codes that has a provider. 
Appendix Figure 1: Teen Birth Rate Trends in Counties with Low Percentage of Providers in 1999

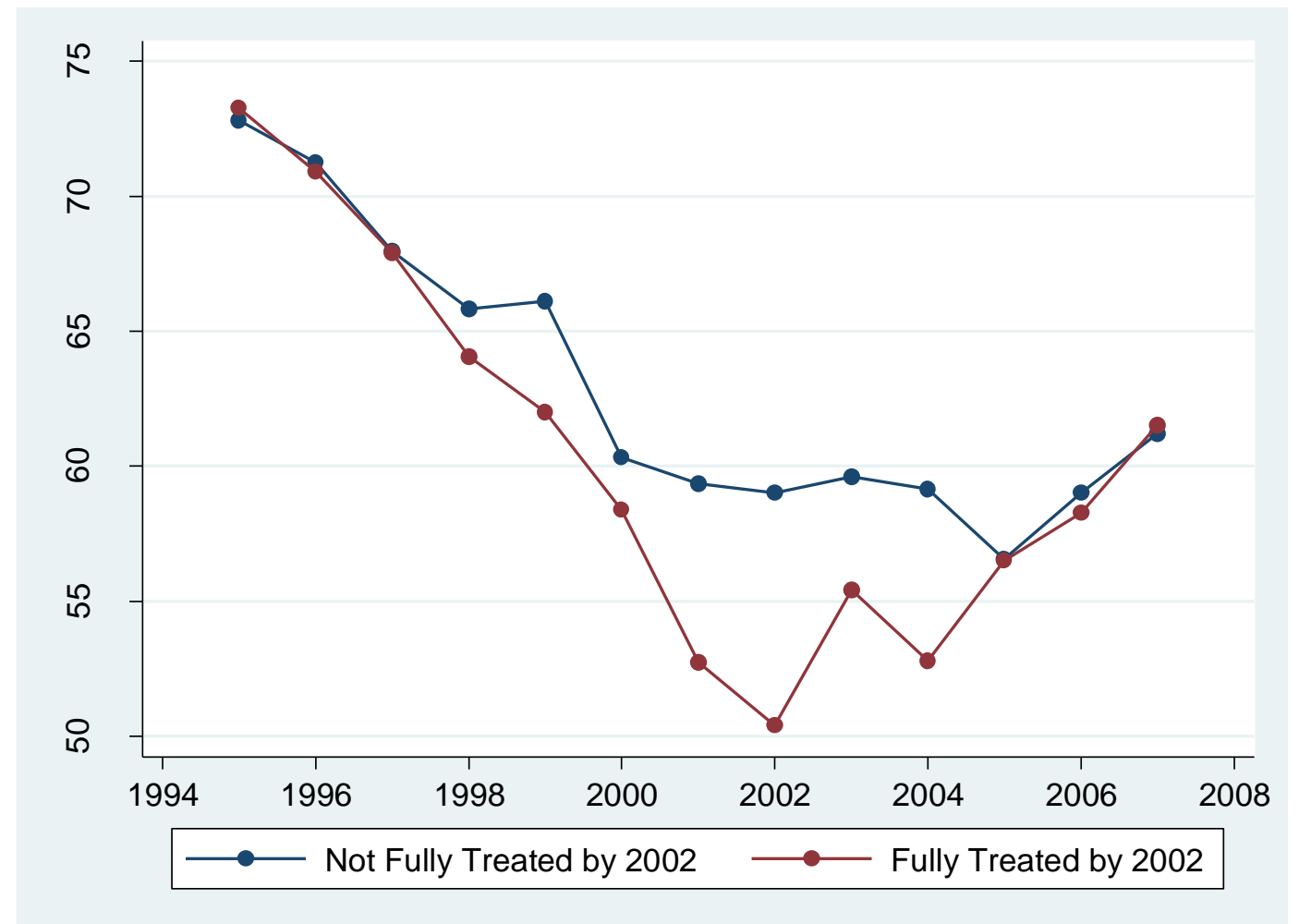

Source: Authors' computation. Counties represented have less than 10\% broadband penetration in 1999. Plotted values represent annual mean teen birth rates in counties with greater than $98 \%$ broadband penetration in 2002 (fully treated) or otherwise (not fully treated). 
Appendix Table 1: Current Broadband Provider influence on Past Teen Births

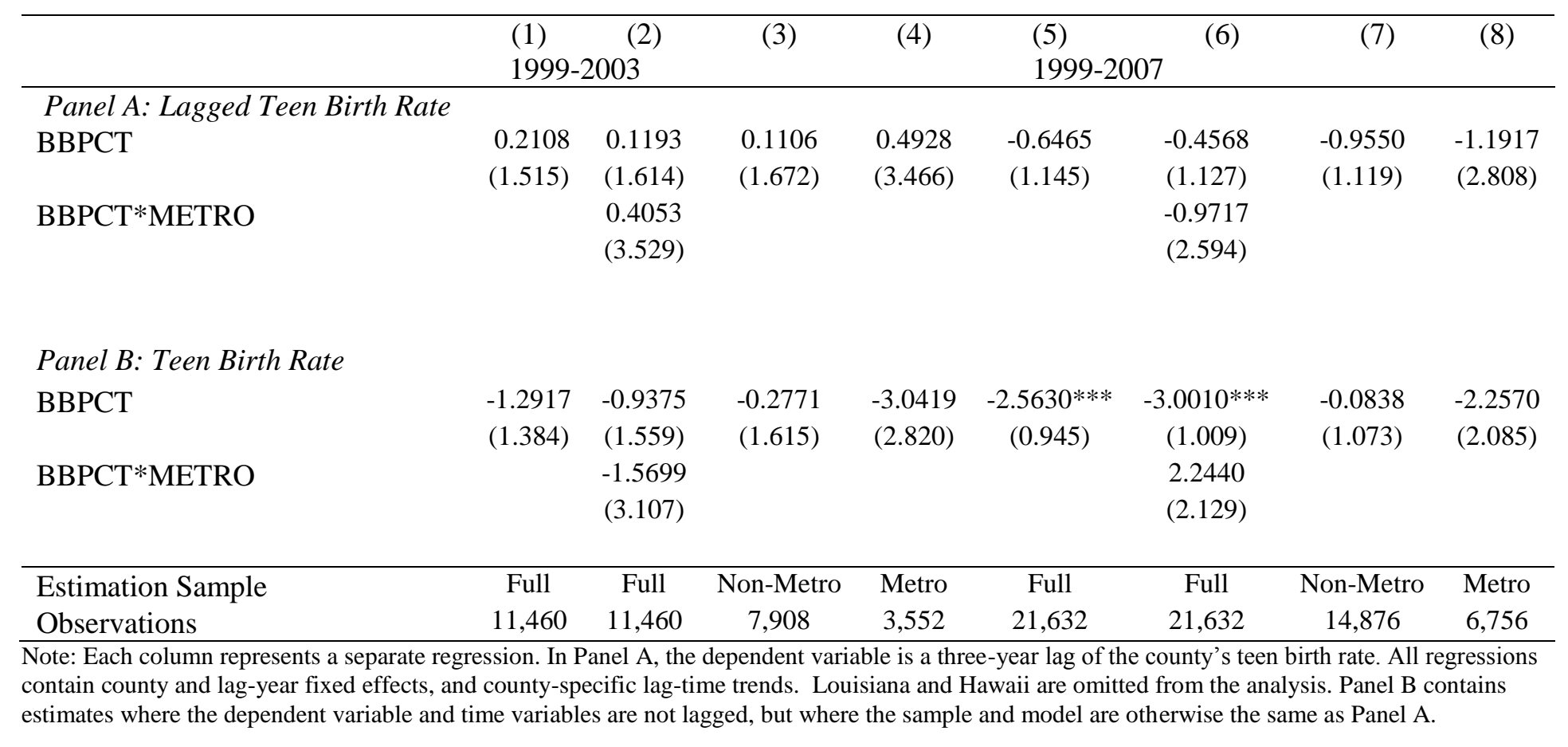

